\title{
A Scenario Analysis Approach to Distributed Energy System Optimisation
}

\author{
P.B. Christopher, L. Aye, T. Ngo and P. Mendis \\ Infrastructure Engineering, The University of Melbourne Australia \\ Email: pbc@unimelb.edu.au
}

\begin{abstract}
This work presents a scenario analysis approach to the planning and optimisation of distributed energy resource systems (DER). Increasing concern relating to the depletion of fossil fuels and the generation of greenhouse gasses from traditional centralised power generation has led to an increased interest in more sustainable distributed technologies. Carbon emission reduction is particularly pertinent in Australia which currently produces more carbon per person than any other developed country in the word and has set the demanding target of $80 \%$ reduction below 2000 emission levels by 2050 (Australian Government, 2008). The primary barrier to the widespread adoption of DER technologies is the long and somewhat uncertain financial return associated with large capital investment. Therefore a need exists to maximise financial return, by selecting appropriate system sizes and technologies for a given load and climate condition. Significant research exists on optimising, planning and evaluating distributed energy systems through mathematical and optimisation models that take into account loads, climate, tariffs and technical performance.
\end{abstract}

Some examples of DER system optimisation at the planning stage include investigation of optimal investment strategies in decentralized renewable power generation under uncertainty. This research forecasted future prices for DER system technologies in addition to feed in tariffs to determine price intervals at which different generator capacities should be installed. Multi-objective optimisation has also been performed for planning and evaluating distributed energy systems by taking into account both $\mathrm{CO}_{2}$ emissions and net present value. Researchers have determined the optimal system combination and corresponding financial and environmental performance of DER systems. Optimisation of system sizing and operation has been performed for a wide variety of intermittent and dispatch-able DER generation systems. DER systems have been optimised for given load and climate conditions whilst guaranteeing reliable system operation using a single year of data at hourly intervals.

The above methodologies assume that the key inputs (load profile, feed in tariffs, usage tariffs etc.) are constant throughout the lifetime of the system. Not only is this definitely not the case but many of the inputs will exhibit significant uncertainty over the systems lifespan. For example if the optimisation of a new cogeneration facility were to be undertaken then the load magnitude and profile that the facility would service could vary each year depending on the rate and nature of development in the new precinct. Additionally other key variables used in determining the financial (and environmental) performance will vary significantly and unpredictably including feed-in tariffs, usage tariffs, thermal load profiles and gas prices. Hence to account for these uncertainties scenario analysis is used to identify the key drivers for each input variable such as building vacancy, recession, advances in energy saving appliances, behavioural changes, policy changes etc. and therefore develop a number of possible future scenarios. Each future scenario provides different input parameters, each varying over the lifespan of the project. Using these final scenarios optimisation can occur to find the most robust or preferred DER system. This can proceed in multiple ways including finding the scenario-weighted optimal solution or the most robust solution across all scenarios.

This paper presents a proposed framework developed to account for long term variability and uncertainty in DER system optimisation. The objective function, constraints and performance modelling methodology are presented in addition to the implementation of scenario analysis in the final optimisation algorithm.

Keywords: Distributed energy systems, micro-grid optimisation, scenario analysis 


\section{INTRODUCTION}

The continuing drive for lower carbon intensive energy infrastructure and the recent increase in thermal efficiencies of distributed generation systems are leading to a focus on decentralised smaller scale distributed energy resource systems (DER). The adoption of multi-generation systems distributed within the grid requires the assessment of economic, environmental and social implications relating to the installation and operation of the systems. Distributed energy resources typically entail decentralised energy production from various types of sources based on local availability such as solar, wind, geothermal and fuel based resources (Chicco \& Mancarella, 2009). Developers have the challenging task of selecting what technology or combination of technologies to implement, the size of the system(s) and their configuration to maximise profitability. Significant research into the system sizing and operation optimisation has already been performed inclusive of co-generation systems, solar photovoltaic's and fuel cells for both financial and environmental outcomes (Beihong \& Weiding, 2006; Mehleri, Sarimveis, Markatos, \& Papageorgiou, 2013; Ren, Zhou, Nakagami, Gao, \& Wu, 2010). The main shortcoming in these optimisation algorithms relates to not considering long term variation in key parameters affecting the system performance and profitability. Hence a scenario analysis method is presented to manage not only future variation in these key parameters but also to provide a more robust, future proof optimal solution.

\section{PROBLEM DESCRIPTION}

Financial profitability for DER systems is strongly linked to several key parameters; the delivered cost of electricity, the price of fuel-stock, feed in tariff rates and the nature and magnitude of the demand profile for which energy is being supplied. All these parameters are associated with significant uncertainty over the lifespan of the power generation system rendering typical single year optimisation algorithms potentially unrealistic over the lifespan of the project. Traditional optimisation solutions inaccuracies are extenuated when there is greater variability in system parameters. These variations should be taken into account in the modelling of such a system however much uncertainty is associated with different parameter's future values. A brief over view of the variability and uncertainty of some of these key parameters in an Australian context is presented below.

The variability of the cost of electricity is shown in Figure 1 for the National Energy Market (NEM). From 1998 to 2008 it would appear relatively predictable rising at rate of approximately 2.7 percent per annum, however from 2008 to 2012 it fell almost 14 percent per year (Sandiford, 2012).. Not only does the wholesale price of electricity vary significantly it also exhibits uncertainty, particularly with longer projections. Natural gas wholesale prices have also shown significant change, from an average price of $\$ 3.60$ per GJ in 2011 up to $\$ 4.77$ per GJ in 2013(AEMO, 2013). Feed in tariffs provided by electricity retailers have even greater uncertainty attached to them due to the politically sensitive nature of mandating minimum prices. Since November of 2009 the net Victorian feed in tariffs for small scale distributed power generators have fallen from 60 cents to just 8 cents per kWh (Australian Government, 2013). Finally electrical and thermal demand profiles perhaps have the greatest uncertainty, being subject to occupancy, user behaviour and demand side technological advances.

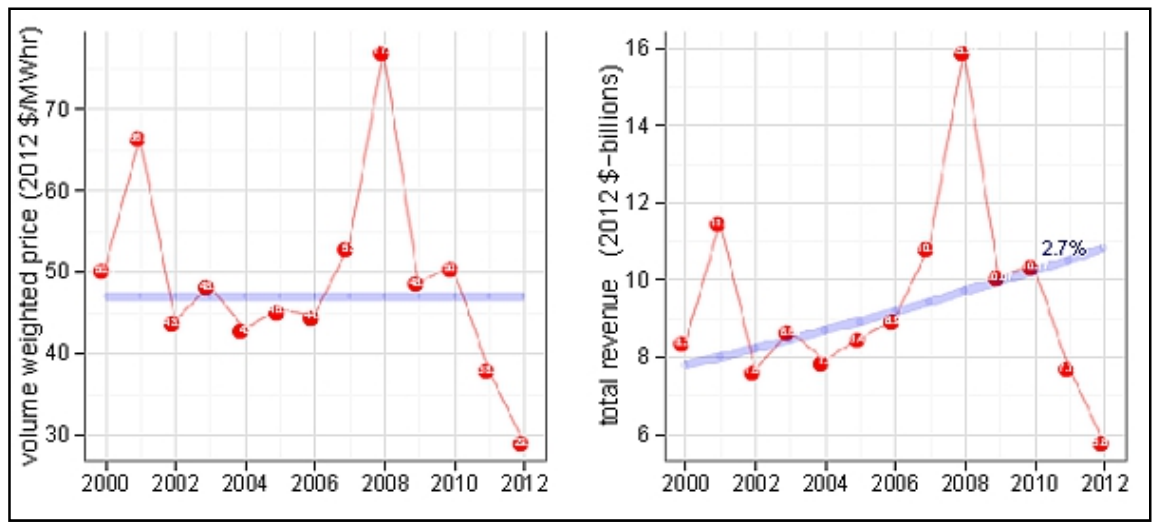

Figure 1: National Energy Market Junee - May (Sandiford, 2012)

Scenario analysis is proposed to tackle both the variability and the uncertainty associated with the relevant variables in DER system optimisation. Several possible future scenarios are generated such that the range of uncertainty is captured, modelled and finally optimised. For example a 'worst case' scenario would choose lower electricity costs and feed in tariffs combined with a lower building energy demand. 
Hence this research builds on existing optimisation models such as (Mehleri, Sarimveis, Markatos, \& Papageorgiou, 2011) with the aim of find the optimal solution for a DER system including time varying parameters with uncertainty for an investor/developer. It is assumed that the following data is obtainable:

- $\quad$ Electrical and thermal demand profile to be supplied at hourly intervals

- Capital costs of all technologies to be assessed in the optimisation

- Performance coefficients of all technologies to be assessed

- Electricity feed in and usage tariffs

- Natural gas tariff prices

- Climate data applicable to the system

The outputs of the optimisation are:

- $\quad$ Sizing of each technology in the DER system

- Electricity and heat temporal profiles of the optimal system

- Net present value of the system

- Levelised cost of electricity

\section{MATHEMATICAL MODEL}

\subsection{Overview}

The scenario analysis framework proceeds in three stages. The first stage involves the formulation of scenarios and the estimation of the effect on each of the key parameters. Secondly each scenario is optimised for the greatest net present value by varying the installed capacity and design configuration for each technology in the DER system. Finally a priority dependent optimal system is selected. For example a risk adverse client may choose the optimised system for a set of 'worst case' variables or a more robust solution by equally weighting each master scenario. An overview of the process is illustrated in Figure 2.

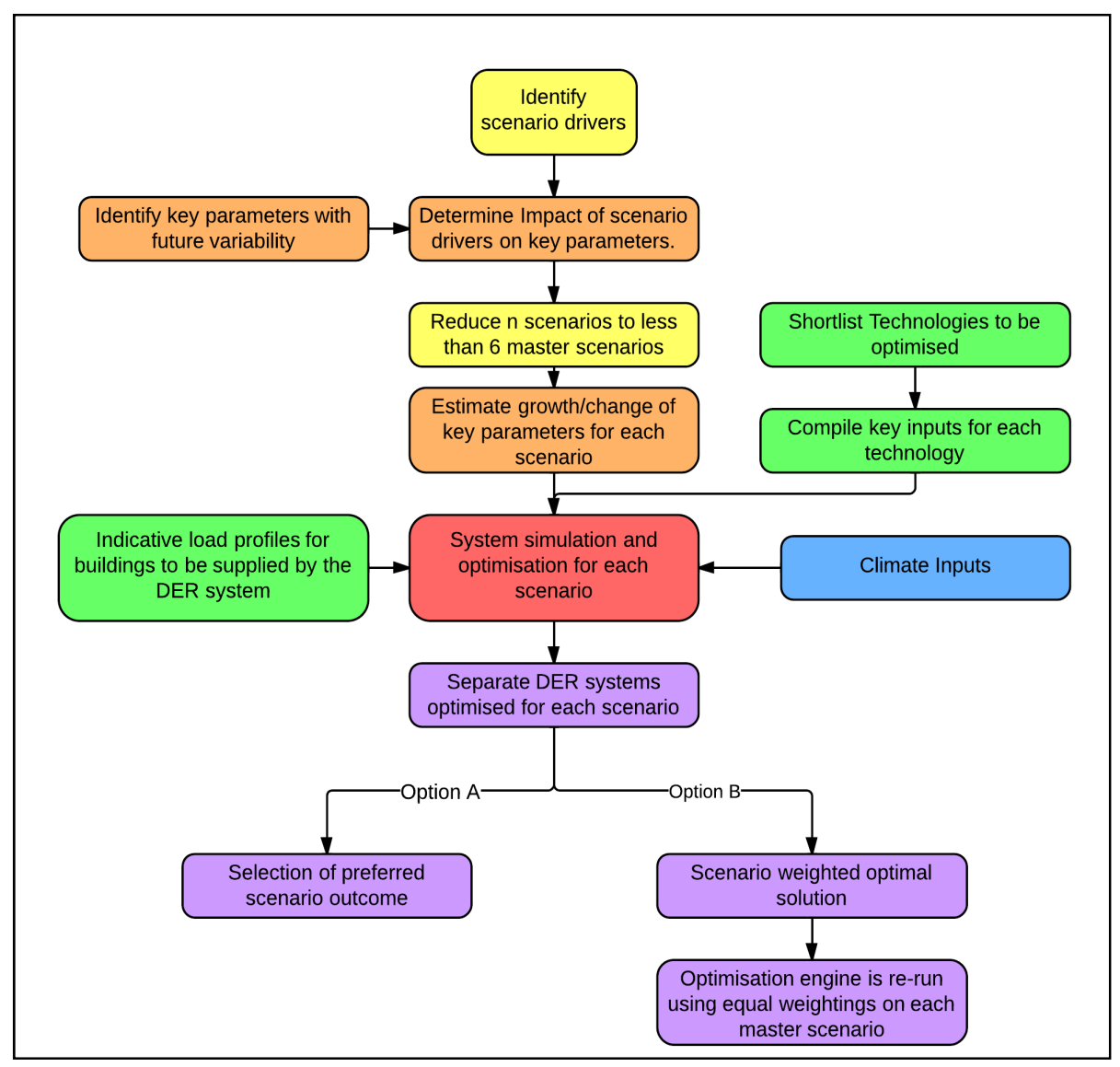

Figure 2: Framework for Scenario Analysis Optimisation 


\subsection{Scenario Formulation}

To begin the scenario formulation process key drivers are identified that may impact the system parameters. Indicative drivers for a DER system include government policy, economic climate, technological advances, land use and user behaviour. Once these drivers are identified the overall effect on each of the parameters in the system is identified. From the effect on each of the system parameters a matrix can be developed showing all possible variations. A simplified example of the parameter variations is shown in Table 1.

Table 1: Scenario Variable Matrix

\begin{tabular}{|l|l|l|l|}
\hline Scenario Variables & \multicolumn{3}{|c|}{ Temporal variation assumption } \\
\hline Demand Growth & Low & Medium & High \\
\hline Feed in Tariff growth & Low & Medium & High \\
\hline Usage Tariff growth & Low & Medium & High \\
\hline Gas Price growth & Low & Medium & High \\
\hline Demand profile & Mostly residential & $\begin{array}{l}\text { Balance of residential } \\
\text { and commercial }\end{array}$ & Mostly commercial \\
\hline
\end{tabular}

As the number of variables subject to uncertainty increases so does the size of the matrix and consequently the optimisation complexity. Hence the total number of scenarios must be reduced from $n$ by $n$ to six or less 'master scenarios'. The reduction in scenarios is intended to capture the range of system performance. Thus with the reduction of these scenarios a list of master scenarios can be developed. An illustrative example is shown in Table 2 with annual variation shown for five master scenarios. It is each of these master scenario's that will be either individually optimised or 'equally weighted and optimised' in order to obtain the system configuration.

Table 2: Master scenarios and key parameters' annual variability

\begin{tabular}{|c|c|c|c|c|c|}
\hline $\begin{array}{l}\text { Scenario } \\
\text { Variable }\end{array}$ & $\begin{array}{l}\text { 1- Worst Case } \\
\text { Residential }\end{array}$ & $\begin{array}{l}\text { 2- Best Case } \\
\text { Residential }\end{array}$ & $\begin{array}{l}\text { 3- Mid range } \\
\text { case }\end{array}$ & $\begin{array}{l}\text { 4- Best Case } \\
\text { Commercial }\end{array}$ & $\begin{array}{l}\text { 5- Worst Case } \\
\text { Commercial }\end{array}$ \\
\hline $\begin{array}{l}\text { Electrical } \\
\text { Demand }\end{array}$ & Low $(-2 \% p a)$ & $\operatorname{High}(2 \% p a)$ & Medium $(0 \% \mathrm{pa})$ & High (2\% pa) & Low (-2\% pa) \\
\hline $\begin{array}{l}\text { Feed in } \\
\text { Tariff }\end{array}$ & Low $(-10 \% p a)$ & $\operatorname{High}(5 \% p a)$ & Medium $(0 \%$ pa) & High (5\% pa) & Low $(-10 \%$ pa $)$ \\
\hline Usage Tariff & Low $(1 \% p a)$ & High $(8 \% p a)$ & Medium (4\% pa) & High ( $8 \%$ pa) & Low (1\% pa) \\
\hline Gas Price & High $(8 \% p a)$ & Low $(2 \% p a)$ & Medium (4\% pa) & Low (2\% pa) & High $(8 \%$ pa) \\
\hline $\begin{array}{l}\text { Demand } \\
\text { profile }\end{array}$ & $\begin{array}{l}\text { Mostly } \\
\text { (75\% residential } \\
25 \% \text { commeridential }\end{array}$ & $\begin{array}{l}\text { Mostly } \text { residential } \\
\text { (75\% residential } \\
25 \% \text { commercial) }\end{array}$ & $\begin{array}{lr}\text { Balance } & (50 \% \\
\text { residential } & 50 \% \\
\text { commercial }) & \end{array}$ & $\begin{array}{l}\text { Mostly commercial } \\
\text { (75\% commercial } \\
25 \% \text { residential) }\end{array}$ & $\begin{array}{l}\text { Mostly commercial } \\
(75 \% \text { commercial } \\
25 \% \text { residential })\end{array}$ \\
\hline
\end{tabular}

\subsection{Objective Function}

The objective function is the net present value (NPV) of the power generation system. Such indicators as capital recovery factor and levelised cost of electricity were deemed less appropriate due to the long term temporal variation in the cash flows. This calculation includes capital and ongoing maintenance costs, electricity and feedstock and surplus power generation cash flow implications. Equation (1) represents the net present value of the system.

$$
N P V_{S Y S}=-\sum_{T n=0}^{T n=n}\left(C_{T n}+O_{N P V_{-} T n}+R_{N P V_{-} T n}+{\operatorname{Rem} \& S a 1_{N P V_{-} T n}}\right)+\text { Elec }_{N P V_{-} S Y S} \quad \text { Equation } 1
$$

The net present value of the system $\left(N P V_{S Y S}\right)$ is equal to the net sum of the future costs and revenue for all selected technologies $\left(T_{n}\right)$ discounted to present value. The net present value of capital costs, operational 
costs, replacement/retrofitting and removal and salvage costs are represented by $C, O, R$ and Rem\&Sal respectively. These costs are dependent on the system size of each technology (which is also the key optimisation outcome. An illustrative example of relating these costs to the optimisation engine will be presented for a solar photovoltaic (PV) system with lifespan 30 years. The capital and installation costs for the solar PV system are represented by $C_{P V}$, where there is no discounting factor as this is expected to occur at year zero as represented in equation 2.

$$
\begin{array}{ll}
C_{P V}=P_{P V} \cdot C k W P_{P V} & \text { Equation 2 } \\
O_{N P V_{-} P V}=\sum_{y=1}^{y=30} \frac{0.01 C_{P V}}{(1+i)^{y}} & \text { Equation 3 } \\
R_{N P V_{-} P V}=\frac{0.1 C_{P V}}{(1+i)^{10}}+\frac{0.1 C_{P V}}{(1+i)^{20}} & \text { Equation 4 } \\
\text { Rem\&Sal }_{N V_{-} P V}=\frac{-0.05 C_{P V}}{(1+i)^{30}} & \text { Equation 5 }
\end{array}
$$

Capital cost the solar PV system is calculated using the peak power capacity in $\mathrm{kW}\left(\mathrm{P}_{\mathrm{PV}}\right)$ multiplied by the $\mathrm{KWp}$ cost factor $\left(\mathrm{CkWp} \mathrm{p}_{\mathrm{PV}}\right)$. Operation and maintenance is assumed to be one percent of capital every year for the lifespan of the project and its' discounted value for the life of the project is represented in equation 3 where $\mathrm{i}$ is the real discount rate chosen for the project. It is assumed that the inverter costs $10 \%$ of the total system cost and is to be replaced every 10 years with the discounted value represented in equation 4 . Removal and salvage at the end of the system life is expected to bring a value (hence the negative sign) of $5 \%$ of the initial capital cost with the discounted value shown in equation 5.

The final term in Equation 1 Elec $_{N P V} S Y S$ represents the net present value of the revenue generated from surplus electricity fed into the grid $\left(\right.$ Grid $\left._{S}\right)$ minus the cost shortfall power drawn from the grid $\left(\operatorname{Grid}_{P}\right)$ as detailed in Equation 6.

$$
\text { Elec }_{N P V_{-} S Y S}=\sum_{y=1}^{y}\left(\sum_{m=J a n}^{m=D e c} 30.4\left[\frac{5}{7}\left(\sum_{h_{W D}=0}^{h_{W D}=24}\left(\operatorname{Grid}_{S}-\operatorname{Grid}_{P}\right)\right)+\frac{2}{7}\left(\sum_{h_{W E}=0}^{h_{W E}=24}\left(\operatorname{Grid}_{S}-G_{\text {Equation } 6}\right)\right)\right] /(1+i)^{y}\right.
$$

Importantly this summation of both feed in and usage tariffs occurs on an hourly basis from both indicative supply and demand curves and is multiplied by the corresponding electricity rate. These hourly costs or revenues are summed over 24 hours for both weekdays $\left(\mathrm{h}_{\mathrm{WD}}\right)$ and weekends $\left(\mathrm{h}_{\mathrm{WE}}\right)$ and are weighted accordingly. One representative weekday and weekend for each month is selected to ensure that the demand profile variation is realistically captured whilst minimising the computational intensity. These costs are summed by multiplying by an average of 30.4 days in the month and repeating for each month in the year. Each year is simulated separately by changing the necessary parameters as detailed in table 2 and discounted to present value over the lifetime of the system ( $y$ years).

\subsection{Constraints}

Certain constraints must be applied to the optimisation to ensure system reliability and sensible results. The first constraint ensures that the net sum of power within the DER system is equal to zero, that is all power generated is either used within the region of demand and/or is fed back into the grid. Where demand exceeds supply the shortfall is then made up by drawing power from the grid. The same is important for heat within the system with the added complexity of heat shortfall being made up by a backup system such as a boiler. A similar methodology to (Mehleri et al., 2011) has been applied to yield the following constraint equations:

$$
\operatorname{Elec}_{h}^{\text {LOAD }}=E_{h}^{\text {Grid }}+E_{h}^{G E N 1}+E_{h}^{G E N 2} \ldots . \quad \forall h_{\text {Equation } 7}
$$


Christopher et al., A scenario analysis approach to distributed energy system optimisation

$$
\text { Heat }_{h}^{\text {LOAD }}=E_{h}^{\text {Boiler }} H E R^{\text {Boiler }}+E_{h}^{G E N 1} H E R^{G E N 1}+E_{h}^{G E N 2} H^{G E N 2} \ldots \quad \forall \text { h Equation } 8
$$

Equation 7 and 8 represent $\left(\operatorname{Elec}_{h}^{L O A D}\right.$ and $\left.\mathrm{Heat}_{h}^{L O A D}\right)$ the electrical and thermal demand for each representative hour. The constraints ensure that the electrical demand is met by the sum of the grid and distributed electricity generators for every hour in the data series. In a similar fashion the thermal demand must also be met, however in this instance a heat to electricity ratio is multiplied by the electrical use of each technology that produces thermal energy.

\subsection{Modelling}

The performance modelling of each technology is critical in order to obtain the optimal size of each technology. Supply side modelling can be dependent upon either natural renewable resources (solar, wind etc.) or required demand. For example solar and wind power will provide electricity irrespective of demand and are modelled simply by applying an efficiency factor to the available resource. A particular solar photovoltaic panel may have an efficiency of $18 \%$ and a DC-AC derate of $77 \%$. Thus these factors are simply multiplied by the available solar resource to obtain power generated. On the other hand co-generation systems are modelled based on supply and demand relationship. For example if the net power demand exceeds that generated by other generators then the cogeneration system will make up the shortfall up to a maximum of its capacity. Again efficiency is used in order to determine the amount of natural gas consumed in addition to the heat generated.

In order for the supply model to function the demand profile must be obtained. The demand profile is a summation of all the different building types utilising the DER system. Some example demand profiles are obtained from the OpenEI (2013) database comprising indicative load curves throughout the USA. The model requires that the demand curves are averaged to two representative days (weekday and weekend) for each month of the year. Depending upon the size of the development to be modelled these usage curves are 'normalised' so that the annual total electricity usage is equal. Sample curves are shown for different building types in Albuquerque NM in January in Figures 3 and 4 below.
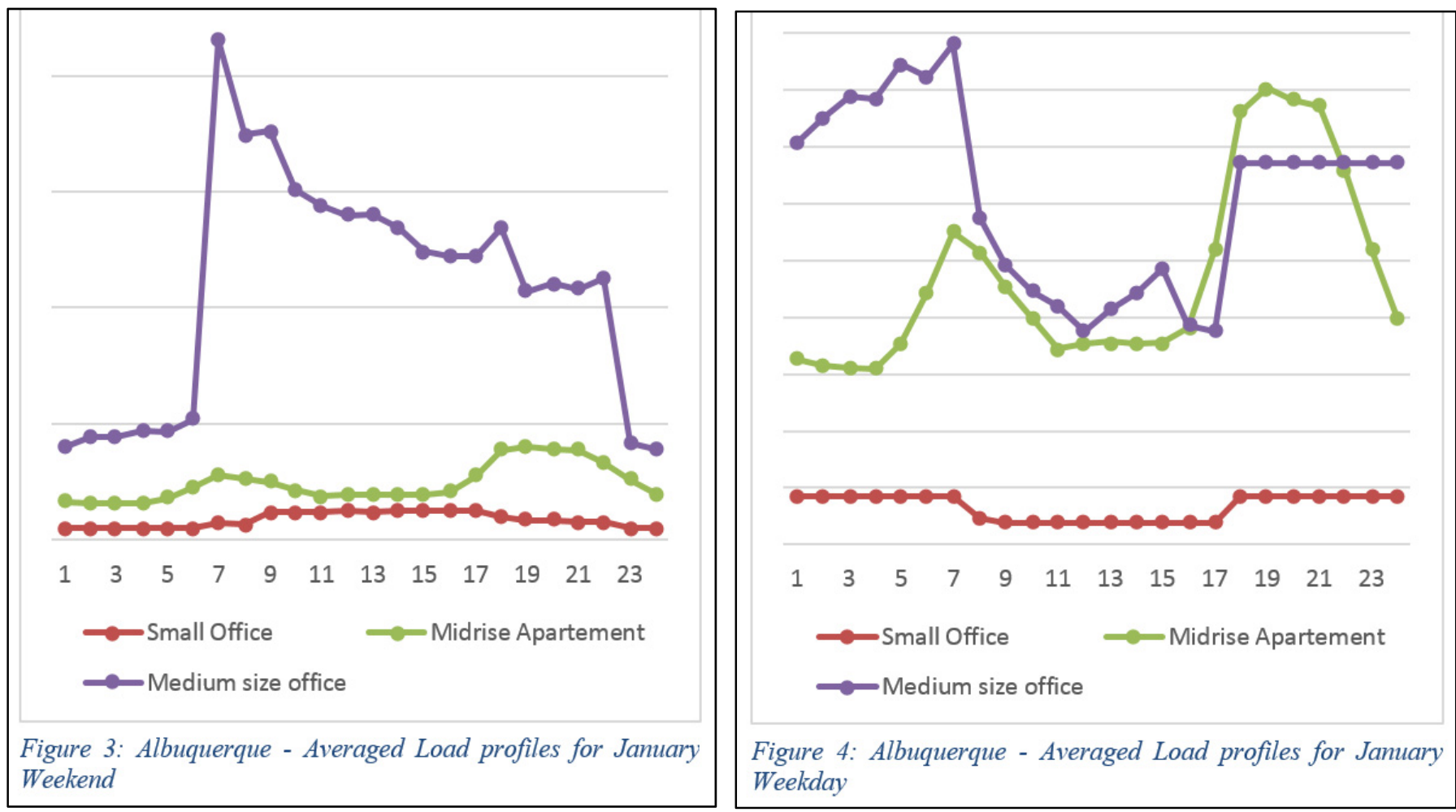

Thus the total electrical energy can be summed over each month in order to obtain the total revenue/costs for each year. The next year in the time series is then calculated by varying the parameters as indicated in Table 2 of master scenarios. This process is completed $n$ times where $n$ is the project lifespan. The optimisation then occurs by changing the system size (such as $\mathrm{P}_{\mathrm{PV}}$ ) for each technology until the net present value of the 
system is maximised subject to the constraints. This will then yield one scenario solution, and if it were the preferred scenario then it would represent the optimal solution.

However where the scenario weighted optimal solution is required the process is quite different. In this instance there are as many objective functions as there are master scenarios. Therefore the average net present value of the solutions must be maximised in order to obtain the optimal robust solution.

\section{CONCLUSION}

A scenario analysis model which accounts for the long term variation and uncertainty in key parameters for the optimal sizing of a DER system has been presented. The model requires hourly electrical and thermal demand profiles in addition to climate, technological and performance characteristics. Master scenarios are formulated and then optimised in order to obtain the optimal DER system for a given temporal variation in key parameters. Finally these master scenarios can each be equally weighted in order to give a robust multiscenario optimal solution. Further work needs to be completed in applying this model to a variety of different case studies and scenarios to determine the divergence of this model from traditional single year approaches.

\section{REFERENCES}

AEMO. (2013, 2013/08/23/05:45:19). AEMO Short Term Trading Market. from http://www.aemo.com.au/Gas/Market-Data/Short-Term-Trading-Market-Datafiles/22/Short-TermTrading-Market-Data.html

Australian Government. (2008). AUSTRALIA'S NATIONAL EMISSIONS TARGET. Retrieved from http://www.apl.au.com/pages/images/CPRS_WP\%20Fact $\% 20$ Sheet_AUS\%20Nat $\% 20$ Emissions $\% 2$ 0Target 151208.pdf.

Australian Government. (2013, 2013/08/06/03:23:37). National targets | climatechange.gov.au. Retrieved 6/08/13, 2013, from http://www.climatechange.gov.au/climate-change/greenhouse-gasmeasurement-and-reporting/australias-emissions-projections/national

files/10/national.html

Beihong, Z., \& Weiding, L. (2006). An optimal sizing method for cogeneration plants. Energy and Buildings, 38(3), 189-195. doi: Cited By (since 1996) 35

Export Date 29 August 2012

Chicco, G., \& Mancarella, P. (2009). Distributed multi-generation: A comprehensive view. Renewable and Sustainable Energy Reviews, 13(3), 535-551. doi: Cited By (since 1996) 85

Export Date 29 August 2012

Mehleri, E. D., Sarimveis, H., Markatos, N. C., \& Papageorgiou, L. G. (2011). Optimal Design and Operation of Distributed Energy Systems. In M. C. G. E.N. Pistikopoulos \& A. C. Kokossis (Eds.), Computer Aided Chemical Engineering (Vol. Volume 29, pp. 1713-1717): Elsevier.

Mehleri, E. D., Sarimveis, H., Markatos, N. C., \& Papageorgiou, L. G. (2013). Optimal design and operation of distributed energy systems: Application to Greek residential sector. Renewable Energy, 51(0), 331-342. doi: http://dx.doi.org/10.1016/j.renene.2012.09.009

OpenEI. (2013). Residential load data e Plus. Retrieved 26/08/2013 http://en.openei.org/datasets/files/961/pub/

Ren, H., Zhou, W., Nakagami, K., Gao, W., \& Wu, Q. (2010). Multi-objective optimization for the operation of distributed energy systems considering economic and environmental aspects. Applied Energy, $87(12), 3642-3651$.

Sandiford, Mike. (2012, 2013/08/23/05:24:01). A spotlight on Australia's great electricity story | Business Spectator. Spectator. from http://www.businessspectator.com.au/article/2012/6/27/climate/spotlightaustralias-great-electricity-storyfiles/12/spotlight-australias-great-electricity-story.html 